\title{
Global OTC pharmaceutical packaging with a local touch
}

\author{
Hannele Kauppinen-Räisänen
}

School of Marketing and Communication, University of Vaasa, Vaasa, Finland, and

Daleen van der Merwe and Magdalena Bosman

African Unit for Transdisciplinary Health Research, North-West University, Potchefstroom, South Africa

\begin{abstract}
Purpose - The aim of this study is to explore the contextual influences of packaging design and its cues on respondents' preferences.

Design/methodology/approach - To explore the contextuality of packaging cues, a multi-attribute valuation technique, conjoint analysis was used for two types of pharmaceutical products (painkiller and sore throat medicine) across seven countries. Data were collected among respondents $(N=461)$ from Finland, Ghana, Mongolia, Nigeria, Portuguese, South Africa and the USA.

Findings - Similarities and dissimilarities were observed between the product types and countries analysed in terms of the impact of packaging cues. The findings demonstrate the global and local nature of brand cues expressed in retail packaging.

Practical implications - The study implies that some cues may serve global markets, while some cues may need to be localised in order to meet the needs of local markets. Understanding these cues and their influences on consumers' brand preferences and choices at the point-of-purchases may enable companies to enter new markets, help them create sustainable and credible global brands.

Originality/value - The study contributes to the existing retail packaging literature and pharmaceutical branding literature by providing empirical evidence of the multidimensional aspects of sensory packaging cues. Second, it contributes by showing the contextual nature of retail packaging and its associated cues for OTC pharmaceuticals.
\end{abstract}

Keywords Brand, Colour, Global, International, Local, Retail packaging

Paper type Research paper

\section{Introduction}

Over the counter (OTC) pharmaceutical products for minor ailments have become increasingly important as a product category for consumers around the world. One contributing factor to this phenomenon is the increased accessibility of these products (Mey et al., 2019). While, in some countries, OTC pharmaceuticals are only available in pharmacies, in others, they have become easily obtainable in grocery stores (Gauld et al., 2015; KauppinenRäisänen et al., 2012). They are available as globally standardised brands marketed in local markets and also as local brands.

The globalisation of brands as a marketing strategy means that custom-made domestic products are both preserved and adapted for local and global appeal based on the assumption that consumers throughout the world have similar needs and evaluate marketing cues in

C Hannele Kauppinen-Räisänen, Daleen van der Merwe and Magdalena Bosman. Published by Emerald Publishing Limited. This article is published under the Creative Commons Attribution (CC BY 4.0) licence. Anyone may reproduce, distribute, translate and create derivative works of this article (for both commercial and non-commercial purposes), subject to full attribution to the original publication and authors. The full terms of this licence may be seen at http://creativecommons.org/licences/by/4.0/ legalcode.

The study (data collection) was partially funded by the Liikesivistysrahasto, Foundation for Economic Education, Finland.

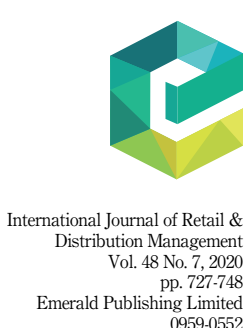

DOI 10.1108/IJRDM-05-2019-0164 
IJRDM

48,7

728 similar ways (Jain, 1989). Considering the dynamic and continually changing nature of consumer markets, retailing and cultural and market diversity (De Meulenaer and De Pelsmacker, 2015; Grewal et al., 2017; Fastoso and Whitelock, 2007; Nacar and Burnaz, 2011; Grewal et al., 2017; Rao-Nicholson and Khan, 2000; Zhou et al., 2015), the local context remains crucial in global brand marketing, creating questions around the marketing of global products in a local context. For OTC pharmaceutical products, globalisation adds further complexity in terms of having to meet the standards of the range of countries in which they are sold (e.g. Babar et al., 2019; Gauld et al., 2015). For instance, they are subjected to rigorous screening processes to meet the safety and quality requirements of these target markets (Babar et al., 2019; Gauld et al., 2015), leaving little opportunity for differentiating global brands at the local level. In essence brands in large global markets have to compete with other global as well as local brands, with a limited possibility to distinguish themselves from their competitors, except, for example, the use of sensory cues incorporated in the packaging.

This study focused on the retail packaging of OTC pharmaceutical products. Retail packaging refers to packaging designed to exhibit the consumer packaged product on the retail shelf. A review of packaging studies reveals the varying impacts of packaging and its extrinsic brand cues, like brand name and price (Bigoin-Gagnan and Lacoste-Badie, 2018; Pecotich and Ward, 2007; Sanyal and Datta, 2011; Veale et al., 2006). However, of these cues, the impact of sensory cues (e.g. visual, haptic and olfactory) has received less scholarly attention, especially in terms of their impact within different contexts, such as brand, product, product type, industry and country (Clement et al., 2013; Kauppinen-Räisänen, 2014; Krishna et al., 2017; Lick et al., 2017; Metcalf et al., 2012; Swahn et al., 2012). In addition, this review reveals that OTC pharmaceutical products for minor ailments have been largely neglected by past research (e.g. Bigoin-Gagnan and Lacoste-Badie, 2018).

The main objective of the study was to explore the contextual influences of retail packaging design and its cues. This was executed by (1) examining the importance attached to packaging cues across product types and countries and by (2) to studying the impact of sensory versus verbal information on respondents' preferences. This study took into consideration two senses in relation to packaging cues: sight and touch. The study investigated retail packages of two types of OTC pharmaceutical products that varied due to sensory cues, namely visual (colour and letter font), haptic (shape) and olfactory (flavour described in words) and verbal cues (manufacturer information, i.e. reputation and countryof-origin). Our research offers a strong international focus, with data stemming from seven different national and cultural settings. We treated packaging as a medium that, through its various cues, influences brand preferences and choices at the point-of-purchase.

With the aforementioned approach, the study addresses the importance of understanding the impact of packaging cues across various national and cultural settings, while also the local impact of those cues on consumer preference and choice behaviour deserves to be acknowledged. From a strategic branding point of view, every single packaging cue being part of the design process deserves to be considered comprehensively. The study introduces a process as a tactic to reach this goal.

\section{Theoretical background}

\section{Consumers' exposure to packaging cues in the marketplace}

Consumers are repeatedly exposed to various brands and products, such as in their living environment, while shopping and in the marketplace (Mueller and Taylor, 2013), which are mostly accompanied by external information, such as brands' and products' retail packaging (Skaczkowski et al., 2016; Swahn et al., 2012).

Within the literature on cue utilisation, packaging is referred to as an extrinsic product cue, which, despite being part of the physical product, can be changed without changing the product and is utilised to evaluate product quality in combination with intrinsic product cues 
(Olsen et al., 2011; Holmes and Paswan, 2012). Product or brand cues expressed on packaging, may culminate in product content expectations, a possible positive connotation of a brand, which may lead to a preference for a brand and even brand choice (Kauppinen-Räisänen et al., 2012; Kauppinen-Räisänen and Jauffret, 2018; Kauppinen-Räisänen and Uusitalo, 2015; Silayoi and Speece, 2007). These extrinsically based choices have posed a challenge for manufacturers, since $70 \%$ of brand decisions are made in a retail store, and $90 \%$ of decisions are based on the visual examination of the retail package (Clement, 2007; Inman et al., 2009). On the one hand, recent research has concluded that the informational elements (e.g. information provided by packaging innovations like gamified packages) of packaging and several extrinsic cues are associated with the cognitive component of decision-making (e.g. Kauppinen-Räisänen, 2014; Krishna et al., 2017; Husić-Mehmedovića et al., 2017; Syräälä et al., 2020). On the other hand, studies have stressed that design elements, such as sensory cues (e.g. graphics, size and shape) relate to affective or emotional responses that arise during decision-making (Kauppinen-Räisänen, 2014; Kauppinen-Räisänen et al., 2012; Krishna et al., 2017; Silayoi and Speece, 2004; Van der Merwe et al., 2013). Therefore, both extrinsic and sensory packaging cues contribute to consumers' quality assessments and choices (Kauppinen-Räisänen and Luomala, 2010; Veale et al., 2006).

Exposure to a multitude of extrinsic and intrinsic packaging cues occurs when these cues or stimuli simultaneously enter the range of consumers' senses and are registered and stored in the their memory for immediate or future use (Friedenberg and Silverman, 2012; Mueller and Szolnoki, 2010; Solomon, 2011). However, in the case of low-involvement decisions, which are made under limited exposure time, repeated exposure is necessary to allow information to become part of consumers' long-term memory (Friedenberg and Silverman, 2012; Mueller and Taylor, 2013), which may assist in choosing products. The present study focused on two specific pharmaceuticals or health products (medication), which could be perceived as highrisk and potentially high-involvement when compared to other consumer goods. However, the involvement of consumers regarding OTC pharmaceuticals may differ: while some consumers may consider them high-involvement, others, for example older persons, may consume them more frequently and regard them as low-involvement. Depending on consumers' levels of involvement with OTC pharmaceuticals upon exposure to packaging, the influence of the cues may differ.

\section{Importance of retail packaging cues in product preference}

During consumers' exposure to extrinsic and design packaging cues, from the cognitive perspective, information processing may result in product preference or greater interest in one product over another similar product, with the possible outcome of a purchase (Hornby, 2005; Schiffman and Kanuk, 2010). Preferred products have a better chance of becoming part of consumers' evoked product set, from which they are likely to purchase within that particular product category (Schiffman and Kanuk, 2010). Packaging cues may, therefore, subconsciously sway consumers' product preferences.

Consumers frequently use country-of-origin (COO) and price as extrinsic verbal and numerical cues when forming opinions regarding product quality, and these cues, therefore, serve as heuristics or shortcuts in product evaluation (Miyazaki et al., 2005; Veale et al., 2006). Research regarding both low- and high-involvement products confirm the greater importance of extrinsic verbal cues (e.g. product information, $\mathrm{COO}$ and manufacturer) than sensory cues (e.g. colour, material and aroma) (Kuvykaite et al., 2009; Silayoi and Speece, 2004) in terms of influencing purchasing decisions based on the importance of concrete information compared to mere images (Silayoi and Speece, 2007). Still, a package's sensory cues are pre-eminent in capturing consumers' attention and in identifying and evaluating product quality, uniqueness and functionality (Nacar and Burnaz, 2011; HusićMehmedovića et al., 2017; Krishna et al., 2017; Silayoi and Speece, 2004; Sogn-Grundvåg
Influences of pharmaceutical packaging 
IJRDM

48,7

and Østli, 2009; Zaichkowsky, 2010). However, consumers' consideration of both intrinsic and extrinsic packaging cues may be affected by their understanding and interpretation of and access to these cues as well as the perceived risk of consumption (Silayoi and Speece, 2004; Veale et al., 2006), as a result of which different consumers may evaluate packaging differently (Silayoi and Speece, 2007).

Packaging cues: to localise or globalise

International trade has increased, and products and services are now globally available. Despite the significant amount of research that has been conducted on this topic, the question of whether products should be marketed in a standardised way or adapted to local requirements (Hussain and Khan, 2013; Wang and Yang, 2011), which would also affect packaging (e.g. Nilsson et al., 2013), remains unanswered. Standardisation promotes innovation and competition between markets while reducing trade barriers (Melewar et al., 2008), which could lead to significant cost saving and reduced consumer prices (Mueller and Taylor, 2013; Ramarapu et al., 1999). Adaption implies that globalised products are positioned in local markets by adapting to their corresponding needs (Nacar and Burnaz, 2011).

The implementation of standardisation poses challenges in that it does not apply to all products and is not an option when irreconcilable differences in physical and political conditions exist (Griffith et al., 2003; Jain, 1989; Medina and Duffy, 1998). For packaging, universally preferred cues need to be identified before they are incorporated into applicable domestic products intended for standardisation. Past research implies that globalised products and package designs should be adapted to accommodate cultural differences, various consumer behaviours and value differences (De Mooij and Hofstede, 2002; Silayoi and Speece, 2007).

Although colour is an example of a sensory packaging cue characterised by similar consumer preferences in many countries, marketers should refrain from directly transferring the colour of a package across markets without considering how it would be perceived in other settings (Madden et al., 2000). Gender differences, for example, were shown to play a significant role in colour preferences in countries such as Canada, China, India and the Netherlands compared to their weaker role in the USA and Turkey (Akcay and Sun, 2013). Furthermore, Asian cultures have a preference for context-dependent product advertisements, while westerners tend to separate products from their context, focussing on product characteristics (Liang et al., 2011). Consumers from different cultures may, therefore, differ in their attitudes towards cues and be more likely to accept stimuli that adhere to their cultural norms; therefore, cues should be adapted for such country-specific differences (Akcay and Sun, 2013; Liang et al., 2011). Thus, global brands benefit from acknowledging the impact of packaging cues and from accommodating potential target countries by including different cultural-dependent characteristics on their brands' retail packaging.

\section{Methodology}

A stated preference experiment employing conjoint analysis (CA) was designed; this method is commonly used to evaluate consumer preferences and predict their choices (Asioli et al., 2016; Hailu et al., 2009; Kim et al., 2014; Meißner et al., 2016; Meyerding, 2016; Silayoi and Speece, 2007; Sonnenberg et al., 2014).

\section{Sampling}

Data were collected between 2012 and 2017 employing a non-probability sampling strategy. The respondents were sampled by means of a strategic purposive and convenience sample procedure. The purposive sampling meant that the sample was selected based on pre-defined characteristics and the aims of the study, while convenience sampling indicated that the 
respondents were easily accessible, available at a given time and willing to participate in the study (Hair et al., 2010). Indeed, non-probability sampling such as that of the current study, allows sampling errors to occur. It has limitations due to its subjective nature in choosing the sample, the limited control over the process, whereby the representativeness of the sample is not guaranteed (Hair et al., 2010). Instead, of representativeness of the sample the current study was interested in reaching a saturation point in the findings, which means that we invited respondents to take part of the study until saturation was reached (Hair et al., 2010). Also, instead of generalisation of findings the study attempted to explore and understand an uncovered issue, whereby the chosen sampling strategy seemed to be appropriate.

Sampling errors cannot be eliminated, yet the careful sampling design and sampling strategy attempted to reduce them. The design involved a clear definition of the characteristics of the sample population included in the study. The study population comprised young adults who shared similar characteristics, specifically respondents who were familiar with the two medicine types used and who intended to use the medicines for minor ailments; at the same time, they were not regular users of the two kinds of medicine and did not have specific brand preferences. The purposeful selection of young adults without regular purchasing habits or preference for these two kinds of OTC medicines allowed for focus on their preferences based on the provided cues instead of their habitual purchasing behaviour. The sampling strategy was selected based on these above criteria $(n=461)$.

The respondents were approached conveniently at or nearby various university campuses in the studied countries. To include a variety of geographic and historical backgrounds, which are the two main drivers of culture, data were collected in Finland (Helsinki), Ghana (Accra), Mongolia (Ulaanbaatar), Nigeria (Abuja), Portugal (Porto), South Africa (Johannesburg) and the USA (Atlanta) (Trentmann, 2009). The countries were located on four continents, represented both developed and newly industrialised and developing countries, and incorporated Asian, Western, and African consumers, of whom the latter has received less scholarly attention so far (Gbadamosi, 2013). The respondents voluntarily participated in the study and were not compensated. Although the study population was not representative of the entire population of the corresponding countries and the findings cannot be generalised, it served the purpose of this exploratory study well.

\section{Experimental design using conjoint analysis}

To explore the contextuality of packaging cues, a multi-attribute valuation technique, conjoint analysis (CA) was used for the two product types for respondents across the seven countries. CA is based on the idea that products and brands can be broken down into multiple sets of attributes (Asioli et al., 2016; Green and Srinivasan, 1990), and that, in a choice situation, consumers make trade-offs between these attributes to state a preference and make a choice. In single-cue studies, respondents show their appreciation for a product's and brand's attributes each attribute at a time; however, instead of measuring single attributes, CA is based on a multi-attribute compositional model that measures several attributes simultaneously (Hair et al., 2010). Yet, CA reveals the influence of each attributes in establishing preferences. In this way, CA overcomes some of the problems associated with single-cue research and is explicitly used for stated preference research in which all the evaluated products and brand attributes are presented together. Hence, CA is used to assess evaluations of different product and brand attributes provided by respondents in a controlled setting, which can then be used to estimate the overall importance of the controlled attributes (e.g. Asioli et al., 2016; Green and Srinivasan, 1990; Hair et al., 2010).

$\mathrm{CA}$ is a procedure that involves different techniques, which means that it is not entirely standardised but is comprised of several conjoint methods (Gustafsson et al., 2003). Thus, there is some complexity and uncertainty regarding its internal workings. CA is also 
IJRDM

48,7

732

criticised for measuring objective attributes alone and excluding the effect of subjective characteristics such as the expected opinions of others and the packaged brands' shelf position, as a result of which it does not sufficiently explain consumers' overall preferences (e.g. Chandon et al., 2009; Kim et al., 2014). Yet, CA was considered to be a feasible technique for the present study, as major brand decisions are made in-store, and nearly all are thought to be based on the visual examination of the package (Clement, 2007; Inman et al., 2009). Moreover, CA is based on the utility theory, whereby it produces utility estimates for the tested attributes (Lancaster, 1966), which further proves its suitability to the current study. The study aimed to obtain insights into what, if any, importance the participants attached to the studied cues in terms of their preference for OTC pharmaceuticals. This type of analysis produces reliable and refined results about preferences for objective attributes using simple ordinal preference data, the reliability of which hinges upon product and brand attribute selection and sample attainment (Hair et al., 2010).

IBM SPSS's orthogonal design and a full-profile method were used to design the experimental product profiles, and a conjoint procedure was used with syntax to analyse the results (IBM SPSS Conjoint 22). The orthogonal design array limits assumptions about the interaction effects between attributes, since it only estimates the primary effects (Gustafsson et al., 1999). Yet, an addition of the interaction component would have increased the number of stimuli (Green and Srinivasan, 1990). A fractional factorial design was used to reduce the number of profiles.

The first step in designing the experiment was to design profiles for the two products: painkillers (four attributes) and sore throat medicine (five attributes). The controlled attributes represented realistic extrinsic cues in the form of verbal and sensory cues expressed as visual and haptic cues. The selection of these attributes for the main experiment was based on a literature review, eight face-to-face interviews with pharmacists and packaging designers, 15 direct elicitations with the help of consumer interviews (Bech-Larsen and Nielsen, 1999), ten in-store observations and two pre-studies of the designed conjoint models. This method, as well as sample triangulation, was employed to establish reliable profiles (Green and Srinivasan, 1990; Hair et al., 2010).

The fractional factorial design reduced the number of full profiles (144 vs. 576) to 16 for both product types, and 16 profile descriptions for data collection were created using the planned card function. The reliability of measuring the impact of sensory cues was considered to hinge upon the stimulus material (Rohani et al., 2014). The profiles were presented as experimental packages, which were tailor-made by a packaging company to mimic real-life choice situations. This approach overcame design challenges related to survey translations in cross-country studies (Cardello, 2005), because the study design only hold words expressing the flavour and manufacturer. Hence, flavour (menthol, honey and lemon, mint and neutral with sweeteners) for the sore throat medicine and manufacturer (both COO (domestic and foreign) and reputation (known and unknown) for the both product types were expressed verbally and translated for each country. The sensory cues for colour (blue, green, yellow and red), shape (elongated, portrait and square) and font (font 1 represented a conservative brand; font 2 , a modern brand; and font 3 , a brand follower) were expressed visually. The price, packaging material, volume and product information on the backs of the packages were identical (Hair et al., 2010).

\section{Data collection procedure}

Non-hypothetical ranking CA was considered appropriate for this study, because it provided information on the consumers' preferences for all the profiles included in a choice set (Akaichi et al., 2013). Moreover, it has been reported that ranking and rating data result in comparable findings (Akaichi et al., 2013; Boyle et al., 2001). 
A script was written to maintain consistency during the data collection sessions. Data collection began by presenting the experimental packages to the respondents and asking them to choose the package they would most prefer in a situation in which they had a minor ailment requiring treatment (i.e. a headache or sore throat). The respondents ordered the conjoint profiles presented as experimental packages according to their preferences - from the most preferred to the least preferred-discriminating between attributes without revealing their degree of appreciation (Almli et al., 2015). Data were collected one-by-one, and each respondent ranked the 16 experimental packages for both products within 15-30 min. Based on the experiences with the two pre-studies, the profiles of product type 1 (painkiller) were ranked first, because the flavour attribute on the package of product type 2 made it easier for respondents to state a preference.

CA produces estimates at individual and aggregated levels, and the aggregated estimates can be analysed after each particular case (Hair et al., 2010). In this way, patterns can be detected as they emerge. Thus, data were collected until a saturation point was reached in the findings, which is methodologically valid for exploratory CA used to determine a clear pattern in responses (Kumar, 2005). Then, the split-half method was used to assess the validity of the findings for the chosen samples, the saturation point, and the stability of the model (Hair et al., 2010).

\section{Results and discussion \\ Sample}

The purposeful sampling strategy ensured that the respondents were familiar with the product types in this study as well as their intended use. None of the respondents were frequent users or purchasers of any pharmaceuticals, and some still lived at their parental homes, in which their parents made their brand decisions. The respondents were aged 18-30 (average age: 26.7 years). The inclusion criteria resulted in respondents' non-frequent use of pharmaceuticals, while their young age allowed them to focus on the packaging cues provided during the data collection sessions instead of responding based on habitual behaviour. The gender distribution was almost equal (female $=52 \%$, male $=48 \%$ ).

The 461 respondents included 50 Finnish, 78 Ghanaian, 51 Mongolian, 99 Nigerian, 60 Portuguese, 75 South African and 48 US respondents.

\section{Results of conjoint analysis}

CA produces estimates at the individual and aggregated levels for determining the relative importance of each attribute based on the part-worth utility for each attribute level for each respondent. In group-level estimates, the analysis computes the total part-worth utilities and relative importance of the total sample by calculating the average of the individual scores. The accuracy of the estimation was determined by the Pearson correlation coefficient, and the correlation between the observed and estimated preferences was determined by Kendall's Tau coefficient. The value of both coefficients was between 0.800 and 0.998 for respondents from all participating countries for the two product types, which indicated a good fit (Hair et al., 2010). Tables 1 and 2 show the correlation scores and aggregated results. Higher mean scores (marked in Italics in Tables 1 and 2) indicated that the cues were assigned more value and perceived to be more important by respondents. The importance scores are visualized in Appendix 1, while the utility scores are visualized in Appendixes 2-4.

Manufacturer and colour were the most important packaging cues (marked in Italics in Table 1) for the painkillers across respondents from all participating countries, except for the Ghanaian respondents, who valued colour the most (36.3\%), followed by shape $(27.5 \%)$ and manufacturer (20.1\%, Table 1). Letter font was the least valued cue, except among the South 
IJRDM

48,7

734

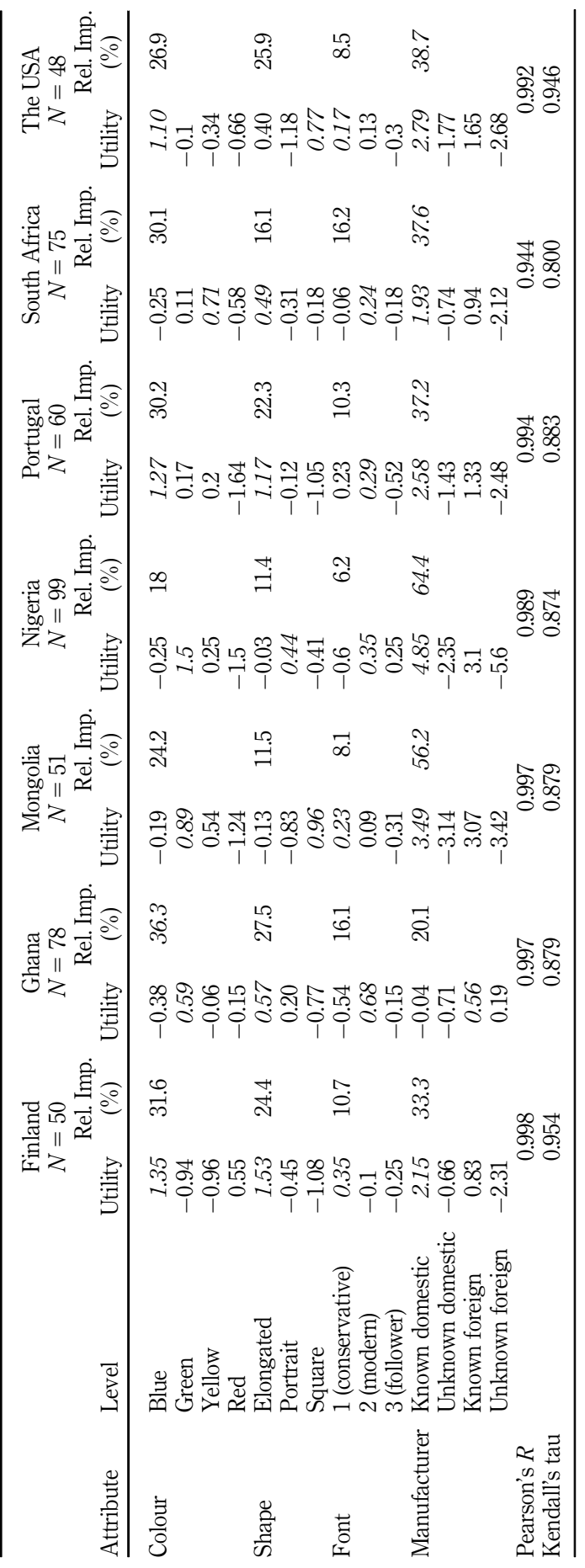

Table 1.

Summary of averaged importance and utility (product type

1. painkillers) 


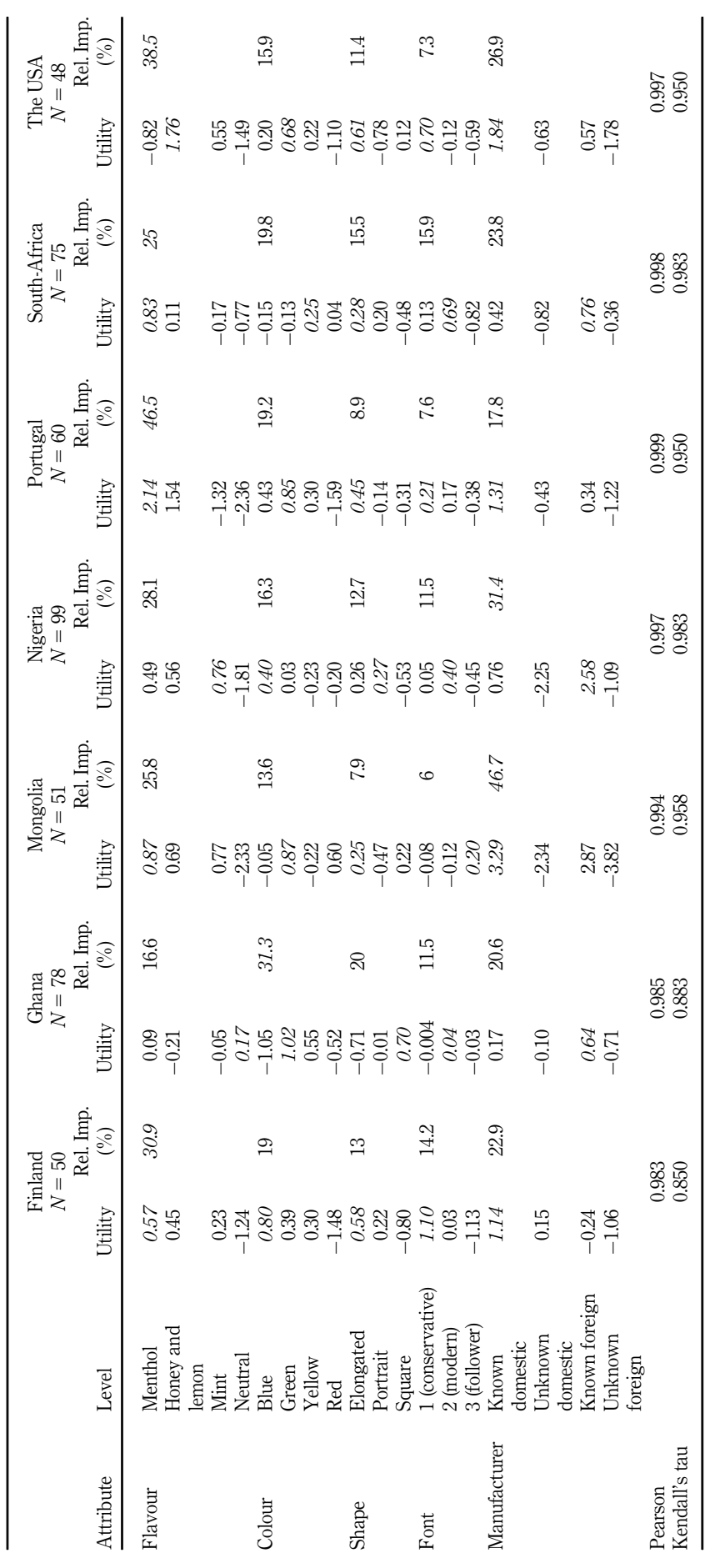

Influences of pharmaceutical packaging

735

Table 2.

Summary of averaged importance and utility (product type 2. sore throat medicine) 
IJRDM

48,7

736

African respondents, who valued shape the least (16.1\%). Thus, verbal information was the most important cue for respondents from all countries, except Ghana, for which sensory cues were the most important.

Table 2 shows more variation in the cue effects with regard to preferences for the sore throat medicine compared to the painkillers. For the Finnish $(30.9 \%)$, Portuguese $(46.5 \%)$, South African (25\%) and US (38.5\%) respondents, flavour affected preference for the sore throat medicine (a lozenge product not wholly swallowed like the painkillers) (marked in Italics in Table 2), while the Ghanaian respondents (31.3\%) valued colour the most. The Finnish (22.9\%), South African (23.8\%), American (26.9\%) and Ghanaian $(20.7 \%)$ respondents indicated that the manufacturer was the second most important cue, while the Mongolian (46.7\%) and Nigerian (31.4\%) respondents valued the manufacturer the most, followed by the flavour. The colour was a secondary cue for the Portuguese respondents $(19.2 \%)$ and a tertiary cue for the Finnish, Mongolian, Nigerian, South African and US respondents. The Finnish and South African respondents valued shape the least, while font was the least important cue for the sore throat medicine for the remaining respondents. Again, for the throat medicine, the order of importance placed on packaging cues (i.e. flavour, manufacturer, colour, shape and font) was similar among all respondents, except for the Ghanaian respondents, for which a localised approach based on colour appears to be valued most. Hence, for most, the verbal cue of flavour exceeds the importance of other cues.

Respondents from all seven countries indicated that colour was the most important sensory cue across the two product types, which highlights the crucial role of colour as a sensory packaging cue (Madden et al., 2000). In particular, colour as a visual cue was more important to respondents than shape, which is a haptic cue. For the Ghanaian respondents, colour remained the most important cue, even when adding flavour as a verbal cue, while the second most important cue was shape for the painkillers, which means that this sensory cue was more significant than the verbal cue in this case.

For the Mongolian and Nigerian respondents, manufacturer remained the most crucial verbal cue, even when adding flavour to the product type like for the sore throat medicine. This finding could mean that respondents from these countries assessed quality based on the manufacturer of the product. These findings could also be explained by the product type. Medicinal products are usually considered high-physical-risk consumer goods, as they relate to a person's health (Solomon, 2011); thus, they require extensive problem-solving and a greater amount of available product information (Schiffman and Kanuk, 2010). For such products manufacturer could be a cue for risk reduction (Miyazaki et al., 2005).

A closer investigation of the utility scores for the pain medication (Table 1) shows that manufacturer's reputation contributed more greatly to desirability than the COO, as the known foreign manufacturer followed the known domestic manufacturer in more cases. Only the Ghanaian respondents valued $\mathrm{COO}$ more than reputation, and, therefore, in their case, a known foreign manufacturer and unknown foreign manufacturer were valued more than domestic manufacturers. The scores for colour showed that respondents from Western countries (Finland, Portugal and the USA) mostly preferred blue for the painkillers, whereas green or yellow was most valued among the African (Ghana, Nigeria and South Africa) and Mongolian respondents. Red was the least valued colour, except among the Finnish respondents. A preference for elongated packaging was evident among respondents from Finland, Ghana, Portugal and South Africa. Moreover, a modern font style was valued among most respondents, except for the Finnish and US respondents.

Menthol was clearly one of the most valued flavours for the sore throat medicine (Table 2). In terms of the emphasis placed on manufacturer characteristics for this product type, the scores show that known domestic manufacturers were valued the most among the Finnish, Mongolian, Portuguese and US respondents, whereas the Nigerian, Ghanaian and South African respondents preferred the well-known foreign manufacturer above the well-known 
domestic manufacturer. The Mongolian, Portuguese and US respondents preferred domestic and foreign manufacturers with a well-known reputation, while the Finnish respondents valued domestic manufacturers more greatly than well-known manufacturers. Again, unknown foreign manufacturers were valued the least, except among the Nigerian and South African respondents, who valued the unknown domestic manufacturer the least. Green was the most valued colour, except among the Finnish and Nigerian respondents, who preferred blue, and the South African respondents, who preferred yellow. The least valued colour varied among the different countries and showed little consistency. In a similar vein to the product type 1 (Table 1), elongated packaging seemed to be preferred by most respondents. For product type 2, the conservative letter style was preferred among the Western respondents, while the African respondents valued the modern style.

\section{Conclusions and implications}

It is well acknowledged that the retail store stimulates consumers' senses. Research has stressed the importance of such stimulation, as it has an impact on retail store appeal, consumer moods, brand and quality evaluations and consumer purchase intentions (Bakamitsos, 2006; Kauppinen-Räisänen and Uusitalo, 2015; Krishna, 2006; 2012; Soars, 2009). Yet, that which has received less attention in the literature is the idea that retail packaging is an integral part of retailing and a product cues existing in retail stores that stimulate consumers' senses (e.g. Hultén, 2012; Kauppinen-Räisänen and Uusitalo, 2015).

Retail packaging exhibit the packaged branded product on the retail shelf and as the "voice" of the brand, it serves various functions. It may convey the performance of the product and the image of the brand at the point-of-purchase. It may also have an impact on the ways in which the retail company appears or how it is perceived (Kauppinen-Räisänen, 2014; Law et al., 2010). Hence, retail packaging may induce a positive packaging experience, contribute to a positive brand experience, enhance a pleasant shopping experience and even contribute to the overall store experience for the consumer (e.g. Hultén, 2012; KauppinenRäisänen and Uusitalo, 2015).

The study focused on the contextuality of retail packaging cues for marketing globalised OTC pharmaceuticals to consumers representing different local conditions. The study detected similarities and differences across the studied product types and countries when it comes to the importance attached to cues expressed in retail packaging in terms of preferences for OTC pharmaceutical products. The study also detected similarities and differences in how sensory versus verbal information influences preferences. Hence, the study entails the essence of understanding the contextuality of the retail packaging cues. For example, the findings show that for the OTC painkiller, for which flavour is not relevant, the manufacturer influences most preferences, followed by colour, except for Ghanaians. For the OTC throat medicine, flavour outweighs for most countries than the importance of the manufacturer. Then again, the sensory cues of colour (i.e. blue and green) and shape (i.e. elongated), including the olfactory cue of flavour (i.e. menthol), expressed verbally, were, to a great extent, of global importance to the respondents, with similarities across most of the countries. However, for respondents from African countries (i.e. South Africa, Nigeria and Ghana) and Mongolia, differences in colour preferences were detected, which imply that a localised branding approach could be beneficial. What more, the findings show the contextuality of shape. Respondents in some countries share the preference for packaging shape, while the shape also is perceived as product type-specific. The visual cue of font, which has received limited received limited scholarly attention, was, in the present study, in most cases, the least important cue, except for the respondents from Finland and South Africa in terms of the throat medicine. This finding does not imply that lettering style is unimportant. On the contrary, the study showed consistencies in font preference among 
IJRDM

48,7

738

Western respondents who shared a preference for the conservative style, which potentially conveys trustworthiness. Respondents from African countries preferred the modern style, which potentially conveys development. The findings imply that throat medicine could benefit more from localised approaches in their packaging cues more than pain medication, especially for Nigerian and South African consumers. The Ghanaian respondents appeared to value localisation for both products more than the other respondents. The exploratory nature of our study does not allow for generalisations, yet the findings imply that packaging cues related to the senses, namely colour, shape, font and flavour, can, to a great extent, be standardised for global markets, with the exception of a few countries.

Despite our specific interest in sensory packaging cues, the importance that respondents, on a global level, attached to verbal information related to manufacturer in terms of product preference deserves special attention. The product type cannot be ignored since respondents from different countries regarded the importance of manufacturer-whether domestic or foreign-differently depending on whether they were assessing painkillers or throat medicine. These differences could be based on the availability of known and trusted local or foreign manufactures of the particular product type as well as on the perceived physical risk associated with that product. The way in which consumers should consume the product (e.g. lozenges versus tablet/capsule) may also play a role, for which the latter instance flavour is not of importance.

The study's contributions to the existing retail packaging literature and pharmaceutical branding literature are two-fold. First, the study advances the two fields of research by providing empirical evidence of the multidimensional aspects of sensory cues expressed in retail packaging. Second, it contributes by showing the contextual nature of retail packaging and its associated cues for OTC pharmaceuticals.

The study provides beneficial insights to pharmaceutical companies - whether at the local or global level. In essence, the findings imply that, while many cues are global, some cues deserve to be considered in the local context. On the one hand, global companies could benefit from paying attention to the impact of packaging cues across various national and cultural settings, while also the local impact of those cues on consumer preference and choice behaviour deserves to be acknowledged. For instance, foreign manufacturers may evoke trust in high-risk products in some countries, while it may evoke a sense luxury or prestige for others. Similarly, domestic manufacturers may represent trust in some countries and low quality in other countries; thus, understanding local context is essential. The colour red may, as a powerful colour, convey an immediate cure in some countries and pain in others. Indeed, from a global strategic branding point of view, every single packaging cue being part of the design process deserves to be considered comprehensively, as this may enable companies to enter new markets and help them create sustainable and credible global brands. On the other hand, local brand and retail management may benefit from understanding what influences consumers' brand preferences and choices explicitly at the point-of-purchase of OTC pharmaceuticals. Management may take advantage of acknowledging the multifunctional packaging and the multidimensional aspects of brand cues expressed in packaging in their attempts to reach and delight savvy consumers with experiences in today's marketplace.

\section{Limitations and future research}

The results also imply the importance of multi-cue fit or cue congruence, because, for colour, green may convey the flavour of menthol or mint. Font also seems to carry importance for brand preferences, which deserves to be explored in future research. This study took into consideration only two senses in relation to packaging cues: sight and touch. While visual cues, such as colour and images, have received some attention in the literature, most sensory cues remain unexplored in terms of their impact on packing. In particular, the sense of touch 
deserves to be further investigated. This study focused on two specific health products (medications), which may be perceived by some consumers as high-risk and highinvolvement when compared to other consumer goods, while others may view these products as low-involvement. To gain a deeper understanding of the effects of product type, both low- and high-involvement products should be further investigated. The current study focused on seven countries, for which it found similarities and dissimilarities between in terms of the impact of packaging cues. Some patterns were detected among developed, newly industrialised counties and some across developing countries. Additionally, some similarities were found among Western and African respondents. These findings indicate that the crosscultural nature of product packaging cue effects should be further investigated, particularly because international trade has been expanding, with global brands competing to establish local or home-grown brands. Furthermore, the inclusion criteria included young age (students) and non-frequent use of OTC pharmaceuticals; thus, results for older and more frequent users of these products may differ and provide potential for future research.

Finally, conjoint analysis is perceived as an essential tool when defining marketing strategies, as it provides insight to understanding the relative importance of various cues. Hence, employing CA enabled the current research to contribute to understanding the contextual impact of a set of packaging cues. Yet, the exploratory nature of the study could be extended to investigate additional packaging cues.

\section{References}

Akaichi, F., Nayga, R.M. Jr and Gil, J.M. (2013), "Are results from non-hypothetical choice-based conjoint analyses and non-hypothetical recoded-ranking conjoint analyses similar?", American Journal of Agricultural Economics, Vol. 95 No. 4, pp. 949-963.

Akcay, O. and Sun, Q.S. (2013), "Cross-cultural analysis of gender difference in product color choice in global markets", Journal of International Business and Cultural Studies, Vol. 7, pp. 158-170.

Almli, V.L., Øvrum, A., Hersleth, M., Almøy, T. and Næsa, T. (2015), "Investigating individual preferences in rating and ranking conjoint experiments. A case study on semi-hard cheese", Food Quality and Preference, Vol. 39, January, pp. 28-39.

Asioli, D., Næs, T., Øvrum, A. and Almli, V.L. (2016), "Comparison of rating-based and choice-based conjoint analysis models. A case study based on preferences for iced coffee in Norway", Food Quality and Preference, Vol. 48, pp. 174-184.

Babar, Z.-U.-D., Gammie, T., Seyfoddin, A., Hasan, S.S. and Curley, L.E. (2019), "Patient access to medicines in two countries with similar health systems and differing medicines policies: implications from a comprehensive literature review", Research in Social and Administrative Pharmacy, Vol. 15 No. 3, pp. 231-243.

Bakamitsos, G.A. (2006), "A cue alone or a probe to think? The dual role of affect in product evaluations", Journal of Consumer Research, Vol. 33, December, pp. 403-412.

Bech-Larsen, T. and Nielsen, N.A. (1999), "Comparison of five elicitation techniques for elicitation of attributes of low involvement products", Journal of Economic Psychology, Vol. 20 No. 3, pp. 315-341.

Bigoin-Gagnan, A. and Lacoste-Badie, S. (2018), "Symmetry influences packaging aesthetic evaluation and purchase intention", International Journal of Retail and Distribution Management, Vol. 46 Nos 11/12, pp. 1026-1040.

Boyle, K.J., Holmes, T.P., Teisl, M.F. and Roe, B. (2001), "A comparison of conjoint analysis response formats", American Journal of Agricultural Economics, Vol. 84 No. 4, pp. 441-454.

Cardello, A.V. (2005), "Commentary: direct versus indirect scaling: the gnashing of psychophysical worldviews", Journal of Sensory Studies, Vol. 20 No. 4, pp. 373-379. 
IJRDM 48,7

Chandon, P., Hutchinson, J.W., Bradlow, E.T. and Young, S.H. (2009), "Does in-store marketing work? Effects of the number and position of shelf facings on brand attention and evaluation at the point of purchase", Journal of Marketing, Vol. 73, pp. 1-17.

Clement, J., Kristensen, T. and Gronhaug, K. (2013), "Understanding consumers' in-store visual perception: the influence of package design features on visual attention”, Journal of Retailing and Consumer Services, Vol. 20 No. 2, pp. 234-239.

Clement, J. (2007), "Visual influence on in-store buying decisions: an eye-track experiment on the visual influence of packaging design", Journal of Marketing Management, Vol. 23, pp. 917-928.

De Meulenaer, S., Dens, N. and De Pelsmacker, P. (2015), "Which cues cause consumers to perceive brands as more global? A conjoint analysis”, International Marketing Review, Vol. 32 No. 6, pp. 606-626.

De Mooij, M. and Hofstede, G. (2002), "Convergence and divergence in consumer behavior: implications for international retailing", Journal of Retailing, Vol. 78, pp. 61-69.

Fastoso, F. and Whitelock, J. (2007), "International advertising strategy: the standardisation question in manager studies: patterns in four decades of past research and directions for future knowledge advancement", International Marketing Review, Vol. 24 No. 5, pp. 591-605.

Friedenberg, J. and Silverman, G. (2012), Cognitive Science: An Introduction to the Study of Mind, (2nd ed.), Sage Publications.

Gauld, N., Bryant, L., Emmerton, L., Kelly, F., Kurosawa, N. and Buetow, S. (2015), "Why does increasing public access to medicines differ between countries? Qualitative comparison of nine countries", Journal of Health Services Research and Policy, Vol. 20 No. 4, pp. 231-239.

Gbadamosi, A. (2013), "Consumer involvement and marketing in Africa: some directions for future research”, International Journal of Consumer Studies, Vol. 37 No. 2, pp. 234-242.

Green, P.E. and Srinivasan, V. (1990), "Conjoint analysis in marketing: new developments with implications for research and practice", Journal of Marketing, Vol. 54 No. 4, pp. 3-19.

Grewal, D., Roggeveen, A.L. and Nordfält, J. (2017), "The future of retailing”, Journal of Retailing, Vol. 93 No. 1, pp. 1-6.

Griffith, D.A., Chandra, A.C. and Ryans, J.K. Jr (2003), "Examining the intricacies of promotion standardization: factors influencing advertising message and packaging”, Journal of International Marketing, Vol. 11 No. 3, pp. 30-47.

Gustafsson, A., Ekdahl, F. and Bergman, B. (1999), "Conjoint analysis: a useful tool in the design process", Total Quality Management, Vol. 10 No. 3, pp. 327-343.

Gustafsson, A., Herrmann, A. and Huber, F. (2003), "Conjoint analysis as an instrument of market research practice", in Gustafsson, A., Herrmann, A. and Huber, F. (Eds), Conjoint Measurement. Methods and Applications, Springer, Berlin, pp. 5-45.

Hailu, G., Boecker, A., Henson, S. and Cranfield, J. (2009), "Consumer valuation of functional foods and nutraceuticals in Canada. A conjoint study using probiotics", Appetite, Vol. 52, pp. 257-265.

Hair, J., Black, W., Babin, B. and Anderson, R. (2010), Multivariate Data Analysis: A Global Perspective, Pearson Prentice Hall, Upper Saddle River, New Jersey.

Holmes, G.R. and Paswan, A. (2012), "Consumer reaction to new package design", The Journal of Product and Brand Management, Vol. 21 No. 2, pp. 109-116.

Hornby, A.S. (2005), Oxford Advanced Learners Dictionary, 7th ed., Oxford University Press, Oxford.

Hultén, B. (2012), "Sensory cues and shoppers' touching behaviour: the case of IKEA", International Journal of Retail and Distribution Management, Vol. 40 No. 4, pp. 273-289.

Husić-Mehmedovića, M., Omeragić, I., Batagelj, Z. and Kolar, T. (2017), "Seeing is not necessarily liking: advancing research on package design with eye-tracking", Journal of Business Research, Vol. 80, November, pp. 145-154. 
Hussain, A. and Khan, S. (2013), "International marketing strategy: standardization versus adaptation”, Management and Administrative Science Review, Vol. 2 No. 4, pp. 353-359.

Inman, J.J., Winer, R.S. and Ferraro, R. (2009), "The Interplay among category characteristics, customer characteristics, and customer activities on in-store decision making", Journal of Marketing, Vol. 73, pp. 19-29.

Jain, S.C. (1989), "Standardization of international marketing strategy: some research hypotheses", Journal of Marketing, Vol. 53 No. 1, pp. 70-79.

Kauppinen-Räisänen, H. and Jauffret, M.-N. (2018), "Using colour semiotics to explore colour meanings”, Qualitative Market Research: An International Journal, Vol. 21 No. 1, pp. 101-117.

Kauppinen-Räisänen, H. and Luomala, H.T. (2010), "Exploring consumers' product-specific colour meanings", Qualitative Market Research: An International Journal, Vol. 13 No. 3, pp. 287-308.

Kauppinen-Räisänen, H. and Uusitalo, O. (2015), "Brand packaging as a visual cue in a service environment", in Gummerus, J. and van Koskull, C. (Eds), The Nordic School: Alternative Perspectives on Marketing and Service Management, Hanken School of Economics, Helsinki, pp. 379-394.

Kauppinen-Räisänen, H., Owusu, R.A. and Bamfo, B.A. (2012), "Brand salience of OTC pharmaceuticals through package appearance", International Journal of Pharmaceutical and Healthcare Marketing, Vol. 6 No. 3, pp. 230-249.

Kauppinen-Räisänen, H. (2014), "Strategic use of color on brand packaging”, Packaging Technology and Science, Vol. 27 No. 8, pp. 663-676.

Kim, H.J., McCleary, K.W. and Park, J. (2014), “The impact of top management's environmental attitudes on hotel companies' environmental management", Journal of Hospitality and Tourism Research, Vol. 38 No. 1, pp. 95-115.

Krishna, A., Cian, L. and Aydinoglu, N. (2017), "Sensory aspects of package design", Journal of Retailing, Vol. 93 No. 1, pp. 43-54.

Krishna, A. (2006), "Interaction of senses: the effect of vision versus touch on the elongation bias", Journal of Consumer Research, Vol. 32, pp. 557-566.

Krishna, A. (2012), "An integrative review of sensory marketing: engaging the senses to affect perception, judgment and behaviour", Journal of Consumer Psychology, Vol. 22 No. 3, pp. 332-351.

Kumar, R. (2005), Research Methodology, 2nd ed., Sage Publications, London.

Kuvykaite, R., Dovaliene, A. and Navickiene, L. (2009), "Impact of package elements on consumer's purchase decision", Economics and Management, Vol. 14, pp. 441-447.

Lancaster, K. (1966), "Change and innovation in the technology of consumption", The American Economic Review, Vol. 56, pp. 14-23.

Law, D., Wong, C. and Yip, J. (2010), "How does visual merchandising affect consumer affective response?", European Journal of Marketing, Vol. 46 Nos 1/2, pp. 112-133.

Liang, B., Runyan, R.C. and Fu, W. (2011), "The effect of culture on the context of ad pictures and ad persuasion: the role of context-dependent and context-independent thinking", International Marketing Review, Vol. 28 No. 4, pp. 412-434.

Lick, E., König, B., Régis Kpossa, M. and Buller, V. (2017), "Sensory expectations generated by colours of red wine labels", Journal of Retailing and Consumer Services, Vol. 37 July, pp. 146-158.

Madden, T.J., Hewett, K. and Roth, M.S. (2000), "Managing images in different cultures: a crossnational study of color meanings and preferences", Journal of International Marketing, Vol. 8 No. 4, pp. 90-107.

Medina, J. and Duffy, M. (1998), "Standardization vs. globalization: a new perspective of brand strategies", Journal of Product and Brand Management, Vol. 7 No. 3, pp. 223-243.

Influences of pharmaceutical packaging 
IJRDM 48,7

Meißner, M., Musalem, A. and Huber, J. (2016), "Eye-tracking reveals a process of conjoint choice that is quick, efficient and largely free from contextual biases", Journal of Marketing Research, Vol. 53, pp. 1-17.

Melewar, T.C., Hayday, D., Gupta, S. and Cohen, G. (2008), "EU enlargement: a case study of branding standardisation”, European Medical Journal of Business, Vol. 3 No. 2, pp. 179-201.

Metcalf, L., Hess, J.S., Danes, J.E. and Singh, J. (2012), "A mixed-methods approach for designing market-driven packaging”, Qualitative Market Research: An International Journal, Vol. 15, pp. 268-289.

Mey, A., King, M., Kelly, F., Grant, G., Townshend, J., Baumann-Birkbeck, L. and Hope, D. (2019), "Australian pharmacy perspectives on increasing access to medicines through reclassification", Journal of Health Services Research and Policy, Vol. 24 No. 2, pp. 81-90.

Meyerding, S. (2016), "Consumer preferences for food labels on tomatoes in Germany - a comparison of a quasi-experiment and two stated preference approaches", Appetite, Vol. 103, pp. 105-112.

Miyazaki, A.D., Grewal, D. and Goodstein, R.C. (2005), "The effect of multiple extrinsic cues on quality perceptions: a matter of consistency", Journal of Consumer Research, Vol. 32 No. 1, pp. 146-153.

Mueller, B. and Taylor, C.R. (2013), "Convergence in global markets: the great standardization versus localization debate is (finally) put to rest”, in Diehl, S. and Karmasin, M. (Eds), Media and Convergence Management, Springer, Berlin, pp. 89-105.

Mueller, S. and Szolnoki, G. (2010), "The relative influence of packaging, labelling, branding and sensory attributes on liking and purchase intent: consumers differ in their responsiveness", Food Quality and Preference, Vol. 21 No. 7, pp. 774-783.

Nacar, R. and Burnaz, S. (2011), “A cultural content analysis of multinational companies' web sites”, Qualitative Market Research: An International Journal, Vol. 14 No. 3, pp. 274-288.

Nilsson, F., Fagerlund, M. and Körner, J. (2013), "Globally standardised versus locally adapted packaging", International Journal of Retail and Distribution Management, Vol. 41 No. 5, pp. 396-414.

Olsen, N.V., Menichelli, E., Meyer, C. and Naes, T. (2011), "Consumers liking of private labels. An evaluation of intrinsic and extrinsic orange juice cues", Appetite, Vol. 56 No. 3, pp. 770-777.

Pecotich, A. and Ward, S. (2007), "Global branding, country of origin and expertise: an experimental evaluation”, International Marketing Review, Vol. 24, pp. 271-296.

Ramarapu, S., Timmerman, J.E. and Ramarapu, N. (1999), "Choosing between globalization and localization as a strategic thrust for your international marketing effort", Journal of Marketing Theory and Practice, Vol. 7, pp. 97-105.

Rao-Nicholson, R. and Khan, Z. (2017), "Standardization versus adaptation of global marketing strategies in emerging market cross-border acquisitions", International Marketing Review, Vol. 34 No. 1, pp. 138-158.

Rohani, L.S., Aung, M. and Rohani, K. (2014), "One step closer to the field: visual methods in marketing and consumer research", Qualitative Market Research: An International Journal, Vol. 17 No. 4, pp. 300-318.

Sanyal, S.N. and Datta, S.R. (2011), "The effect of country of origin on brand equity: an empirical study on generic drugs", The Journal of Product and Brand Management, Vol. 20 No. 2, pp. 130-140.

Schiffman, L.G. and Kanuk, L.L. (2010), Consumer Behaviour, 10th ed., Pearson, Upper Saddle River, NJ.

Silayoi, P. and Speece, M. (2004), "Packaging and purchase decisions: an exploratory study on the impact of involvement level and time pressure", British Food Journal, Vol. 106 No. 8, pp. 607-628.

Silayoi, P. and Speece, M. (2007), "The importance of packaging attributes: a conjoint analysis approach”, European Journal of Marketing, Vol. 41 Nos 11/12, pp. 1495-1517. 
Skaczkowski, G., Durkin, S., Kashima, Y. and Wakefield, M. (2016), “The effect of packaging, branding and labeling on the experience of unhealthy food and drink: a review", Appetite, Vol. 99, January, pp. 219-234.

Soars, B. (2009), "Driving sales through shoppers' sense of sound, sight, smell, and touch", International Journal of Retail and Distribution Management, Vol. 37 No. 3, pp. 286-298.

Sogn-Grundvåg, G. and Østli, J. (2009), "Consumer evaluation of unbranded and unlabelled food products: the case of Bacalhau", European Journal of Marketing, Vol. 43, pp. 213-228.

Solomon, M.R. (2011), Consumer Behavior: Buying, Having, and Being, 9th ed., Pearson, Boston, Mass.

Sonnenberg, N.C., Erasmus, A.C. and Schreuder, A. (2014), "Consumers' preferences for eco-friendly appliances in an emerging market context", International Journal of Consumer Studies, Vol. 38, pp. 559-569.

Swahn, J., Mossberg, L., Öström, A. and Gustafsson, I.B. (2012), "Sensory description labels for food affect consumer product choice", European Journal of Marketing, Vol. 46 Nos 11/12, pp. 1628-1646.

Syrjälä, H., Kauppinen-Räisänen, H., Luomala, H.T., Joelsson, T.N., Könnölä, K. and Mäkilä, T. (2020), "Gamified package: extending value of brand engagement", Journal of Business Research, In press, doi: 10.1016/j.jbusres.2019.11.089.

Trentmann, F. (2009), "Crossing divides: consumption and globalization in history", Journal of Consumer Culture, Vol. 9 No. 2, pp. 187-220.

Van der Merwe, D., Viljoen, S., de Beer, H., Bosman, M. and Kempen, E. (2013), “Consumers' experiences of cold chain food packaging: a qualitative study among women in South Africa", International Journal of Consumer Studies, Vol. 37 No. 6, pp. 650-57.

Veale, R., Quester, P. and Karunaratna, A. (2006), "The role of intrinsic (sensory) cues and the extrinsic cues of country of origin and price on food product evaluation", in 3rd International Wine Business and Marketing Research Conference, Refereed Paper, Montpellier, pp. 6-8, available at: http://academyofwinebusiness.com/wp-content/uploads/2010/05/Veale.rtf.pdf (accessed 10 September 2017).

Wang, X. and Yang, Z. (2011), "Standardization or adaptation in international advertising strategies: the roles of brand personality and country-of-origin image", Asian Journal of Business Research, Vol. 1 No. 2, pp. 25-36.

Zaichkowsky, J.L. (2010), "Strategies for distinctive brands”, Journal of Brand Management, Vol. 17 No. 8, pp. 548-560.

Zhou, L., Poon, P. and Wang, H. (2015), "Consumers' reactions to global versus local advertising appeals: a test of culturally incongruent images in China”, Journal of Business Research, Vol. 68 No. 3, pp. 561-568.

(The Appendix follows overleaf) 
IJRDM

48,7

744

Figure A1a.

Summary of averaged importance (product type 1 , painkillers)
Figure A1b.

Summary of averaged importance (product type 2 , sore throat medicine)
Appendix 1

70

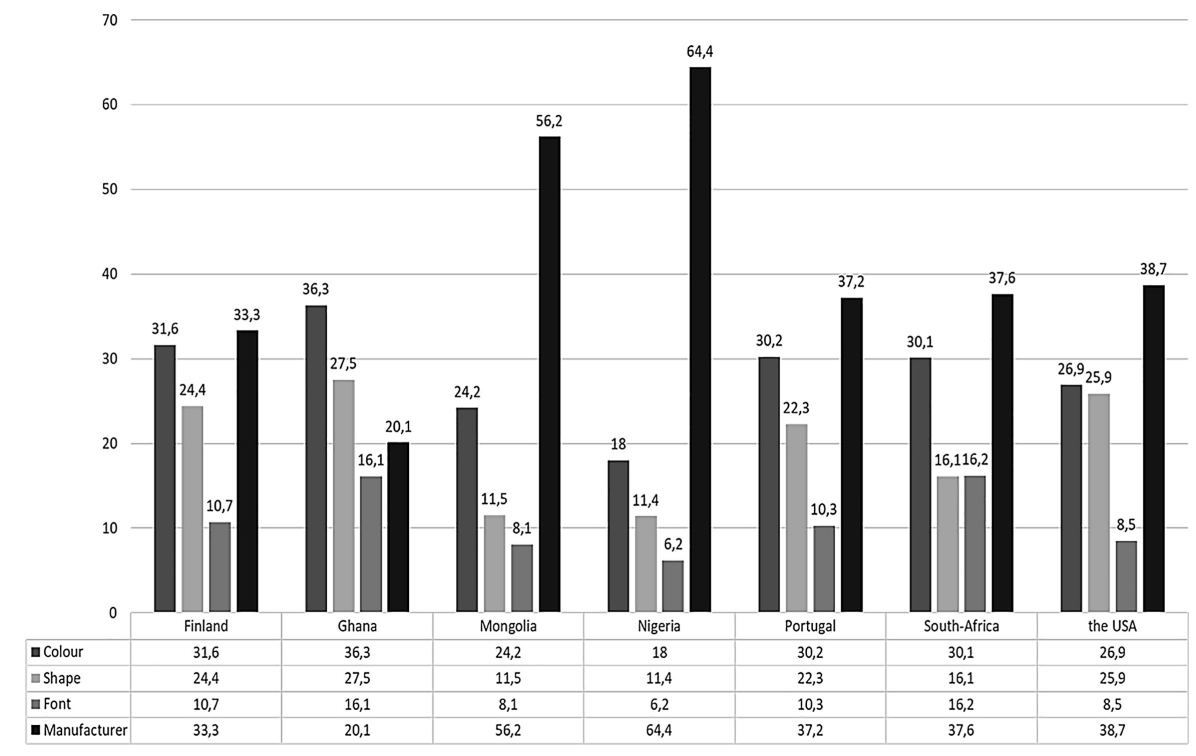

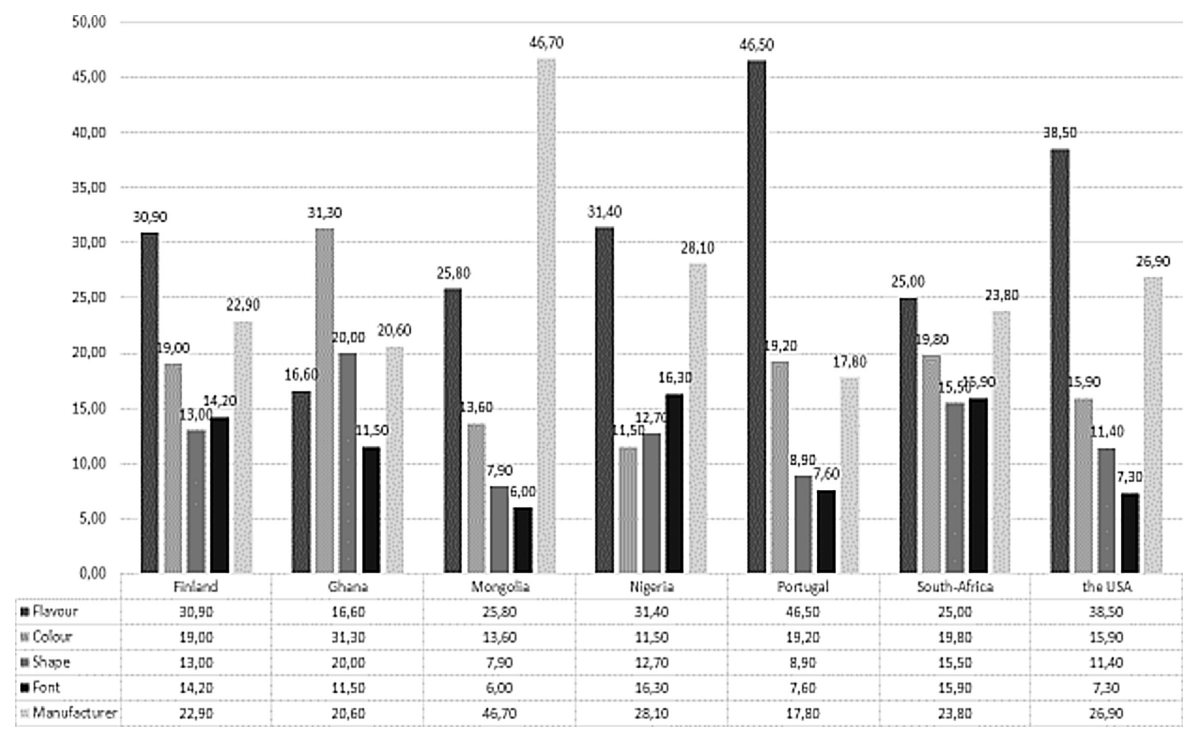




\section{Appendix 2}
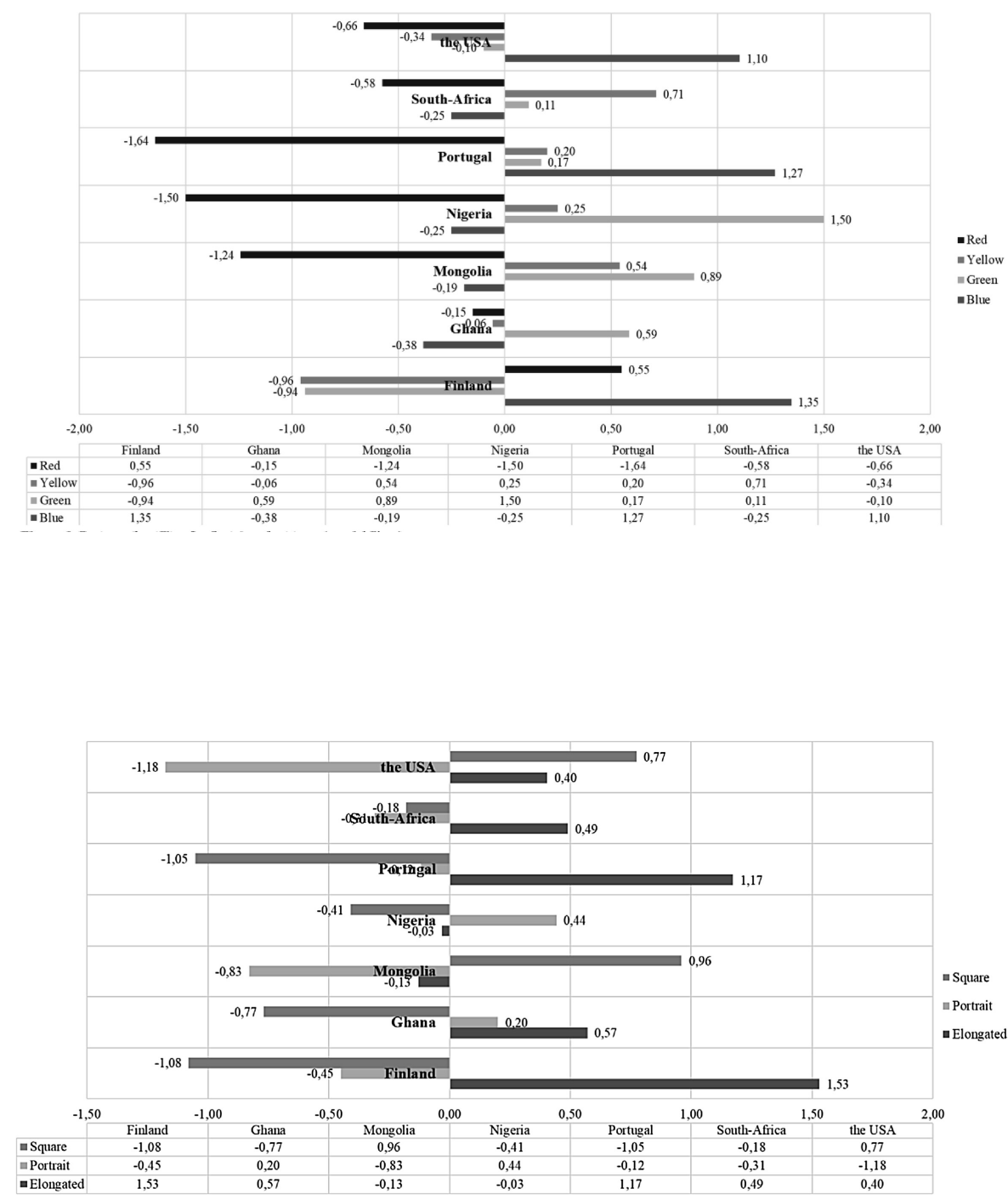

Influences of pharmaceutical packaging

Figure A2a. Part-worth utility for color (product type 1, painkillers)
Figure A2b.

Part-worth utility for shape (product type 1 , painkillers) 
IJRDM

48,7

\section{6}

Figure A2c.

Part-worth utility for font (product type 1, painkillers)

Figure A2d.

Part-worth utility for manufacturer (product type 1, painkillers)
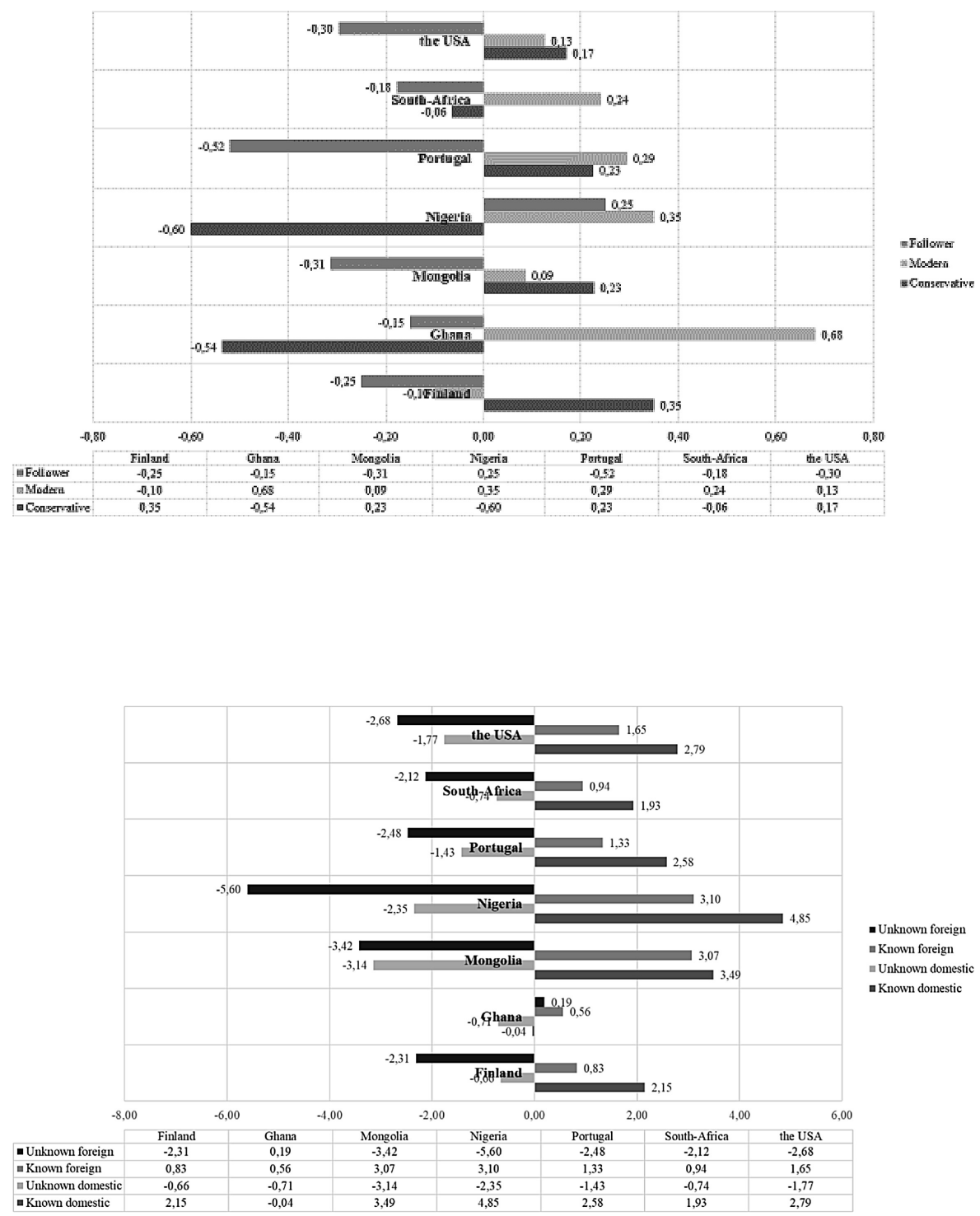


\section{Appendix 3}
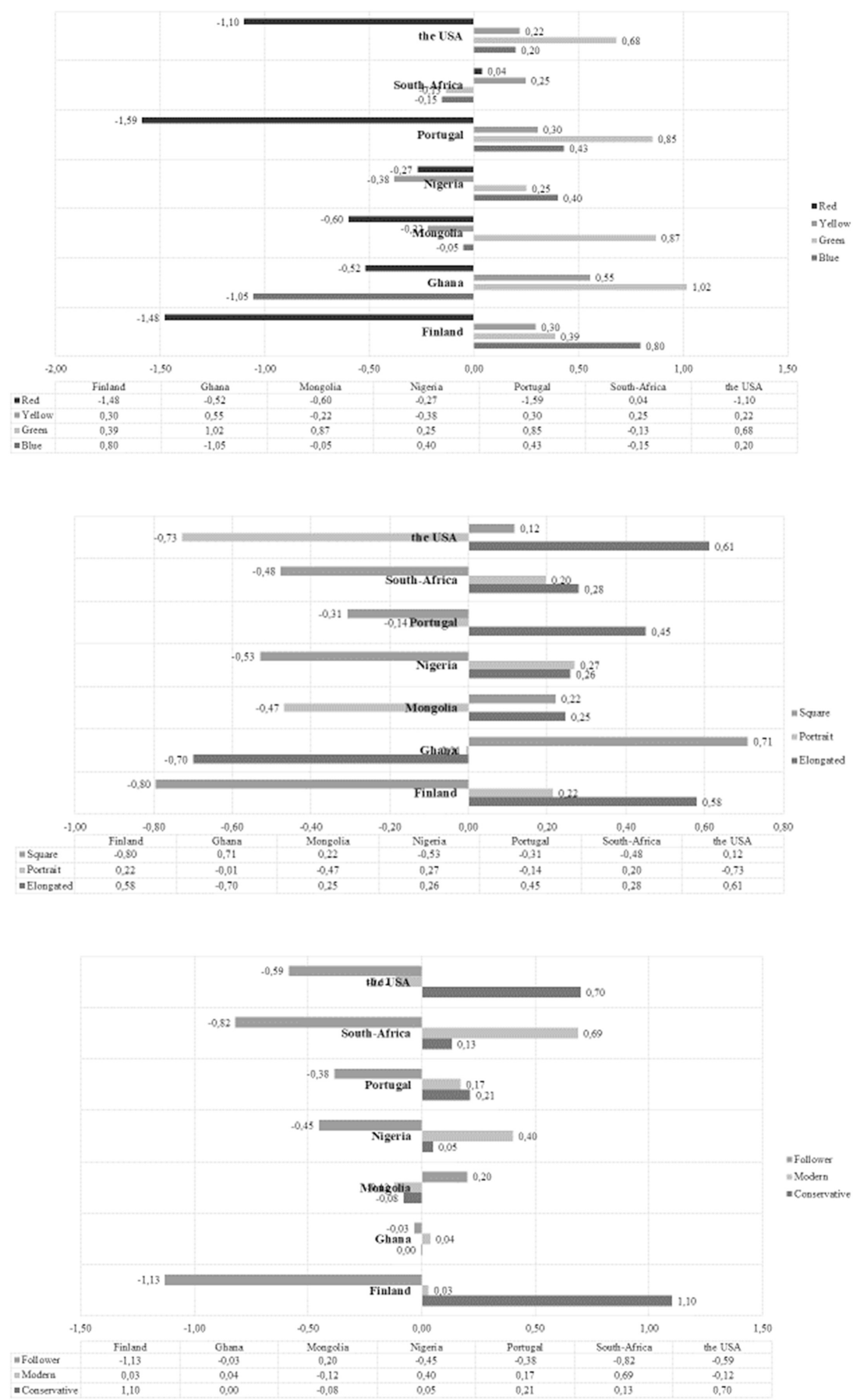

Influences of pharmaceutical packaging

Figure A3a.

Part-worth utility for color (product type 2 , sore throat medicine)
Figure A3b.

Part-worth utility for shape (product type 2 , sore throat medicine)
Figure A3c. Part-worth utility for font (product type 2 , sore throat medicine) 
IJRDM

48,7

\section{8}

Figure A3d.

Part-worth utility for manufacturer (product type 2 , sore throat medicine)
Figure A4a.

Part-worth utility for flavour (product type 2 , sore throat medicine)

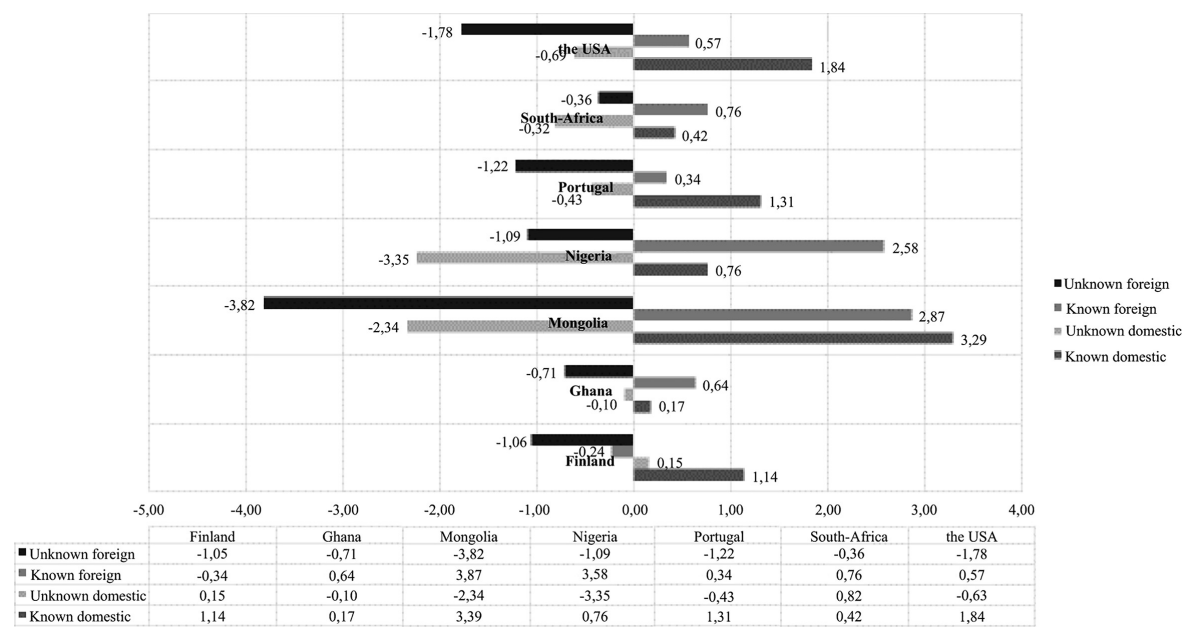

\section{Appendix 4}

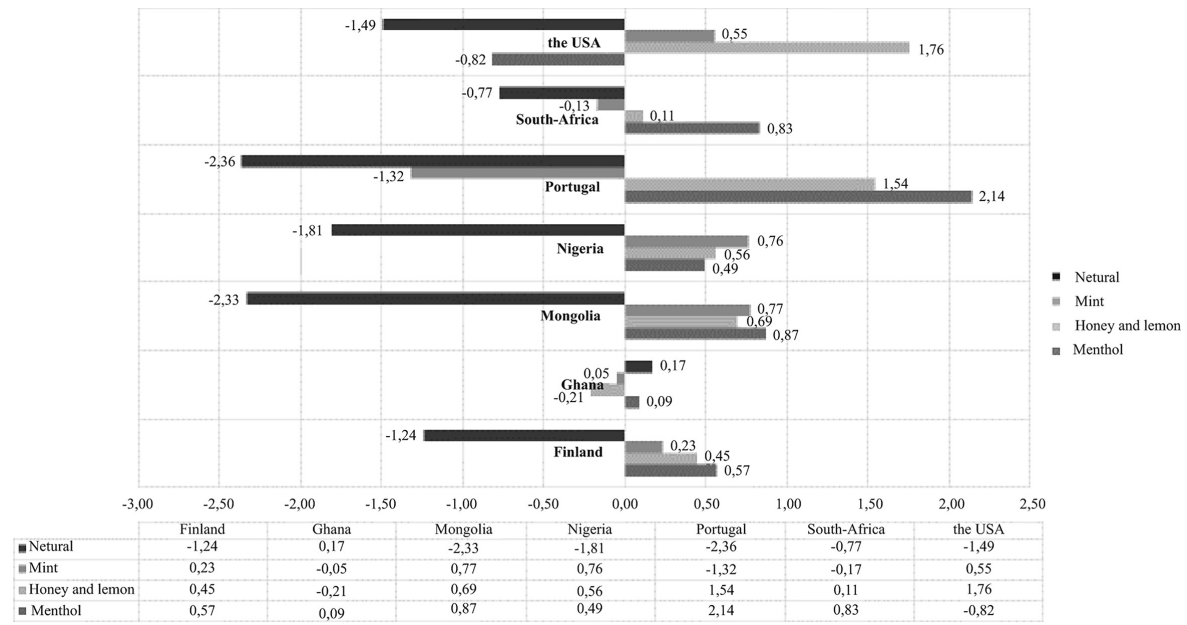

Corresponding author

Hannele Kauppinen-Räisänen can be contacted at: hannele.kauppinen-raisanen@uva.fi

For instructions on how to order reprints of this article, please visit our website: www.emeraldgrouppublishing.com/licensing/reprints.htm Or contact us for further details: permissions@emeraldinsight.com 